ее предпочтениями, а также имеющимися навыками. Одни дети обладают навыками работы с техникой, они берут на себя организацию фотографирования и видеосъемки наиболее важных событий в жизни класса или группы, другие компетентны в области работы с компьютерной техникой, они способны работать с информационным сопровождением, размещать оперативную информацию о наиболее заметных событиях (олимпиадах, конференциях), размещают в социальных сетях конспекты занятий, необходимые учебные материалы. В такой деятельности, поддерживаемой педагогом, учащиеся становятся не только сопричастными к организации работы, но и отрабатывают те навыки, которые могут пригодиться во взрослой жизни.

Развитию личности в ситуации самореализации и действий является проектная деятельность. Индивидуальность ребенка проявляется в данном случае в возможности выбора темы исследования, маршрута работы, стратегии представления результатов работы, выбора методов исследовательской деятельности. Помимо групповой работы в данной методике актуализируется личный контакт учащегося с педагогом, который может разворачиваться в формате подготовки статьи, презентации, доклада. Исследовательская деятельность как основа социализации в школе является основополагающей в трудах Н. Поповой. В качестве ведущего элемента технологии использовалась исследовательская деятельность. Ребенок становится исследователем окружающего мира. В зависимости от возраста задания усложнялись. Если изначально нужно было провести экскурсию в почтовом отделении, хлебопекарне и т.д., то затем школьник и водили экскурсии на вокзалы, заводы, мастерские. Ученики старшей школы исследователи окрестные деревни, где изучали особенности местного быта, обычаи. При исследовании ученики придерживались схемы: сбор материала посредством исследовательской работы- изучение и анализ полученного материалаоформление результатов.

Таким образом, применение современных воспитательных диалоговых и игровых технологий педагог не только обобщает и углубляет знания учащихся, готовит их к участию в проектной деятельности, всероссийских олимпиадах, государственной итоговой аттестации, но способствует воспитанию личности, формированию социально активной гражданской позиции, эрудиции, способности и готовности отстаивать свою точку зрения в конкурентной борьбе, вносит существенный вклад в выявление и формирование одаренности учащихся, способствует с помощью создания развивающей среды самореализации и признанию одаренных детей в обществе.

$$
* * *
$$

1. Волосков И.В. Инновационные методы воспитания в системе дополнительного образования// Материалы VI Международной практической конференции: «Церковь и казачество: соработничество на благо Отечества».-М.: МВ-Пресс, 2017.-с. 138-142 (0,5)

2. Концепция духовно-нравственного воспитания, развития и социализации обучающихся в казачьих кадетских корпусах.- М.: МГУТУ, 2017.-С.17

\title{
Евтыхова Н.М. \\ К вопросу о подготовке будущих учителей начальных классов в условиях дистанционного обучения
}

Адыгейский государственный университет (Россия, Майкоп)

doi: 10.18411/scienceconf-11-2021-13

\section{Аннотация}

В статье представлены некоторые мысли по обучению математике будущих учителей начальных классов в условиях дистанционного обучения; по проблемам дистанционного формата обучения и возможных путях их решения. 


\section{Abstract}

The article presents some thoughts on teaching mathematics to future primary school teachers in the conditions of distance learning; on the problems of distance learning format and possible ways to solve them.

Массовый переход всех образовательных учреждений на дистанционную форму обучения в период карантина вызвал шквал эмоций различного рода. Появилось большое количество публикаций в этом направлении, несмотря на то, что исследования по дистанционному обучению ведутся давно, с тех самых пор как компьютер вошел в жизнь каждого человека. Так еще в восьмидесятые годы прошлого века, по утверждению Б. Холмберга, данный формат был достаточно распространен в Австралии, а концу первого десятилетия уже XXI века такие технологии использовались почти в каждом университете в США и множестве учреждений высшей школы в Европе [2]. Разными аспектами дистанционного обучения занимались многие российские и зарубежные исследователи (М.Ю. Бухаркина, Т.П. Зайченко, Д. Киган, М.В. Моисеева, М. Мур, Е.С. Полат, Э.Г. Скибицкий,А.В. Хуторский и др.). Как отмечают Г.И. Вергелес, и О.А. Граничина: «в отечественной педагогике дистанционное обучение рассматривается и как технология, и как новая форма обучения, и даже как вариант заочного обучения» [1]. Мы безусловно солидарны с утверждением этих авторов о том, что одним из основных условий успешного дистанционного обучения в начальной школе является: «готовность всех субъектов образовательного процесса в начальной школе - образовательной системы, государства, образовательного учреждения, учителя начальных классов, родителей и, наконец, учащихся начальных классов» [1].

Готовность учителя начальных классов зависит от его умения свободно владеть современными компьютерными технологиями, смартфонами и их приложениями. Наибольшие затруднения испытывают учителя старшего поколения. Но молодые, начинающие педагоги, недавно вышедшие из стен университета, совершенно свободно владеют современной техникой и, очень быстро осваивают компьютерные технологии. При этом, оказывается, что опытный учитель, обладая хорошей теоретикометодической подготовкой, не всегда может эффективно организовать учебную деятельность и донести необходимый объем информации в условиях дистанционного обучения. А молодой учитель, наоборот, владея современными компьютерными технологиями, не могут эффективно организовать учебную деятельность школьников, в силу недостаточной теоретико-методической подготовленности. В связи с этим усиливается роль университетского образования будущих учителей начальных классов. Новые требования предъявляются к преподавателям вузов, которые должны обладать такими компетенциями, которые позволят подготовить студентов к будущей профессии в условиях как очного обучения, так и дистанционного.

В настоящее время практический каждый вуз применял дистанционную форму обучения в разных форматах. Но вынужденный переход полностью на дистанционный формат в условиях карантина выявило ряд проблем, с которыми столкнулось практически все педагогическое сообщество.

Вначале это были трудности организационного характера, которые были достаточно быстро преодолены. Так, в нашем вузе элементы дистанционного обучения уже применялись ранее, на платформе Moodle, которое нашло свое продолжение в новых условиях. Было организовано проведение он-лайн занятий, а также зачетноэкзаменационной сессии с помощью платформы Zoom.

Затем стали проявляться проблемы, влияющие на качество обучения. Эти проблемы освещены в публикациях многих методистов - педагогов. Начнем с технических проблем. Во-первых, у каждого преподавателя должен быть в наличии набор технических средств, для успешного проведения занятий. Несмотря на то, что 
названные выше платформы обладают некоторыми возможностями передаче информации, специфика предмета «Математика» предполагает написание формул, выполнение чертежей, решение задач и т.п. что не всегда удачно получается. Требуются дополнительные приспособления и подключения, например, параллельного подключения планшетов, смартфонов, использование «Zoom+Документ камера» и т.д. все это требует дополнительных материальных затрат, порой очень солидных и не всегда подъемных для преподавателей, а тем более для студентов. Обратная связь также технически не всегда возможна, даже менее возможна, так как не у всякого студента есть возможность не только приобретения гаджетов и приложений, но и полноценной интернет связи. Многие студенты, можно сказать в большинстве своем, связывались с лектором с помощью смартфонов, что также не совсем удобно: маленький экран, плохая видимость формул и чертежей, невозможность решать математические задачи с помощью экрана телефона и т.д. В конце концов, «привязанность к розетке» может привести к внезапному прерыванию текущей лекции, потери информации.

Во-вторых, как отмечают многие исследователи, проблемой является также, отсутствие живого общения вне проведения видеоконференций. Если на сайте выложен весь учебно-методический комплекс, то не всегда есть возможность у студентов уточнить непонятные моменты в изучении нового материала, в ходе решения задач и т.д. Специфика изучения теоретических основ начального курса математики отражается в том, что требуется постоянное взаимодействие теоретического и методического материалов, обсуждения отражения положений математики в учебниках для начальной школы. И только непосредственное общение в этом случае, оказывается наиболее эффективным.

В-третьих, профессия учителя начальных классов предполагает способность к публичным выступлениям. Учитель начальных классов должен уметь сам и научить детей общаться на языке того предмета, который они преподают. Важнейшей частью математического образования является овладение будущим учителем грамотной математической речи, как устной, так и письменной, способностью передать возможности математического языка детям, а это также невозможно без непосредственного общения участников учебной деятельности. Такое общение необходимо и в дуэте преподаватель-студент: проговаривание многих положений, определений, доказательств, применение их к начальному образование есть важнейшая составная часть математической подготовки будущих учителей начальной школы.

В-четвертых, отмечается проблема отсутствия самомотивации и самодисциплины, особенно у первокурсников. Они еще не осознают значимость выбранной профессии и не всегда понимают выбор предметов для изучения. Математика, как правило, для студентов, выбравших профессию учителя начальных классов, представляется одним из самых трудных дисциплин. Зачастую набранные баллы ЕГЭ по этому предмету не самые высокие и присутствует внутренний страх перед самим предметом. В условиях дистанционного обучения, мы наблюдали случаи, когда при проведении видеоконференций, некоторые студенты ставили какую-либо картинку в заставку «аватарку» а сами занимались своими делами. Преподаватель не всегда понимает: присутствует слушатель на лекции или нет. На вопросы, задаваемые аудитории реагирует один или два человека. Есть один плюс в этой ситуации: если лекция записывается и обучающиеся в конце ее сохраняют, то существует зыбкая надежда, что студент позже, в более приемлемой для него обстановке просмотрит ее. Если же информация представлена в виде прикрепленной лекции заранее, то, учитывая тенденцию последних лет - нежелание читать, а тем более читать научный математический текст или даже его просматривать, нет уверенности, что студент изучит предлагаемый материал. Трудно заменить рассказ умелого преподавателя, 
позволяющего сложный и скучный, на первый взгляд материал, преподнести с увлечением, адаптируя к избранной профессии.

В-пятых, выполнение и оценивание контрольных материалов зачастую не объективно, по вполне объективным причинам. Практика показала, что некоторые недобросовестные студенты, копировали чью-либо работу и пересылали ее как свою, в некоторых случаях одна и та же работа присылалась с разных адресов. Иногда при ответе на вопросы экзамена по смартфону, параллельно считывался материала с компьютера, при этом утверждалось, что нет возможности отвечать с помощью компьютера. Бывали случаи, когда находилось решение задач в недрах интернета (а это делается сейчас очень быстро) и выдавалось как собственное решение. Есть, конечно, система тестов, особенно по математике, но они скорее пригодны в большей степени для промежуточного контроля. Тотальный переход к тестовому контролю не приводит к ожидаемым результатам. Например, задание: «Объясните с точки зрения аксиоматического, теоретико-множественного подходов, а также с точки зрения «число как результат измерения величин» числовое равенство 12:4=3. В каких ныне действующих учебниках по математике для начальной школы они реализуются?» лучше выполнить при непосредственном обсуждении. А , например, задачу: «Построить трапецию по четырем сторонам с помощью циркуля и линейки, соблюдая все этапы решения задачи на построение» трудно решить в тестовом варианте. Это же касается решений задач на доказательство, истолкований выбора действий при решении арифметических задач и т.д., т.е. задач, где важен не только и не столько ответ, а ход решения, способы рассуждений. Когда отсутствует личное общение, преподавателю сложно объективно оценить выполненную работу и понять: насколько усвоен студентами материал.

В - шестых, преподаватель должен сам хорошо владеть основами компьютерной грамотности, быстро включаться в новые информационные форматы, чтобы эффективно осуществлять образовательную деятельность. Это привело к необходимости самообучения, к которому в нашем вузе подключились компетентные молодые программисты. Они организовали срочные он-лайн курсы, снабдили всевозможными методическими рекомендациями и приходили на помощь всякий раз, когда это требовалось.

Этот список проблем можно продолжить, и в основном они носят общий характер для многих дисциплин. В силу того, что мы оказались в условиях дистанционно-очного обучения, очевидно, требуется найти пути наиболее эффективного использования возможностей обучения разных форматов. Так, например, дистанционное обучение помогает тем студентам, которые находятся на очно-заочной или заочной форме обучения; студентам, в силу обстоятельств, находящихся на очной форме обучения, но с правом свободного посещения занятий. В ходе дистанционного обучения при проведении лекций в виде видеоконференций очень удобно демонстрировать какие-то видеоролики, красочные рисунки, он-лайн использование интернет ресурсов и т.д. Но ничто не сможет заменить живое слово преподавателя, его эмоциональное состояние, энергетический взаимообмен от непосредственного общения.

Наш опыт показал, что основной формат обучения, все же должен быть очным. Но на случай необходимости дистанционного обучения должен быть создан весь пакет учебно-методического комплекса. По дисциплине «математика» он содержит: курс лекций, курс практических заданий с образцами решения задач, система самостоятельных, контрольных работ, тестов, вопросы к экзаменам и зачетам; видеоматериалы к лекциям. Мы полагаем, что в случае необходимости решений задач на построение, на доказательство, обоснование выбора действий и т.д., требующих практических действий или участия преподавателя в случае оф-лайн, можно использовать готовые цифровые образовательные ресурсы (их достаточно много представлено в электронном виде) и видеозапись лекций. В настоящее время такой 
комплекс находится в стадии доработки. Часть его уже используется в учебном процессе, другая часть - в стадии апробации.

Так, с 10 декабря 2020 г. по 31 декабря 2022 г. по Постановлению Правительства РФ от 07.12.2020 N 2040 «О проведении эксперимента по внедрению цифровой образовательной среды» на территории четырнадцати субъектов РФ проводится эксперимент по внедрению цифровой образовательной среды в сфере общего образования, среднего профессионального образования и соответствующего дополнительного профессионального образования, профессионального обучения, дополнительного образования детей и взрослых. Очевидно, что интеграция цифровых решений в деятельность образовательной организации - это не возвращение к дистанту, а дополнительный механизм реализации образовательной деятельности и важнейшая задача в рамках реализации государственной стратегии цифровизации российской экономики. [3]. В вузах такая модель обучения используется наряду с традиционной.

$$
* * *
$$

1. Вергелес, Г.И. Дистанционное обучение в начальной школе: за и против / Г.И. Вергелес, О.А. Граничина//Начальная школа - №2-2021 - 3-6 - текст непосредственный

2. Гончарова, 3.Г. Дистанционное обучение как инновационная модель преподавания математики в высшей - текст электронный / З.Г.Гончарова URL: https://cyberleninka.ru/article/n/distantsionnoeobuchenie-kak-innovatsionnaya-model-prepodavaniya-matematiki-v-vysshey-shkole

3. Савичева, Е. В. Цифровизация школы - это возвращение дистанта или рывок в будущее?- текст электронный /E.B. Савичева - URL:https://pravo-prosv.ru/files/pегиональный.pptx

\section{Петренко А.А. \\ Образовательные тренды как ориентир развития компетенций современного учителя}

ФГБОУ ВО РГУ имени С.А. Есенина (Россия, Рязань)

doi: 10.18411/scienceconf-11-2021-14

\section{Аннотация}

В статье обосновываются современные требования к развитию профессиональных компетенций учителя на основе анализа научных педагогических исследований. Представлена технология, содержание методической деятельности по развитию компетенций педагогов в школе. Рассматриваются образовательные тренды как ориентир выбора содержания методической работы, отвечающего потребностям современного общества: тенденции развития образовательного процесса.

Ключевые слова: учитель, компетентный учитель, компетентность, методическая работа, содержание методической деятельности, образовательные тренды, тенденции развития образовательного процесса, командообразование.

\section{Abstract}

The article justifies the modern requirements for the development of teacher's professional competencies based on the analysis of scientific pedagogical research, the regulatory framework of state educational policy in Russia. Technology, content of methodological activities on development of competencies of teachers in school are presented. Educational trends are considered as a guideline for choosing the content and organization of methodological work in a school that meets the needs of modern society: trends in the development of modern teacher education.

Keywords: teacher, competent teacher, competence, methodical work, content of methodical activity, educational trends, trends of development of educational process, team building. 